\title{
The Genetic Basis of Actidione Resistance in Neurospora
}

\author{
By K. S. HSU \\ Department of Biological Sciences, Stanford University, \\ Stanford, California, U.S.A.
}

(Received 13 December 1962)

SUMMARY

Seven actidione-resistant mutants recovered from separate strains of Neurospora crassa are due to mutations of single genes at either of two loci: act-1 (located between nit-1 and aur in linkage group I) and act-2 (located close to $s p$ in linkage group V). Mutant alleles at both loci are dominant over their wild-type alleles in heterokaryons. Both genes are located in well marked chromosome arms, and scoring is distinct.

\section{INTRODUCTION}

Antibiotic-resistant mutants have been used routinely in bacterial genetics since Demerec (1945) demonstrated the mutational origin of penicillin resistance in Staphylococcus aureus. However, no such mutants have been reported in Neurospora crassa. The usefulness of drug-resistant mutants for genetic studies in such fungi as Aspergillus nidulans (Roper \& Käfer, 1957), and the recent finding that Neurospora mutants resistant to the acridine dye acriflavine are controlled by chromosomal genes which can be used as markers, initiated the attempt to test several categories of drugs, including a number of antifungal antibiotics, with the aim of recovering useful markers. Mutants resistant to actidione have been found. The genetic basis of resistance and sensitivity to this antibiotic is presented in this paper. (A preliminary account of some of these results has been given [Hsu, 1962, and Neurospora Newsletter, 1, 5].) Actidione resistance due to genic difference has previously been reported in Saccharomyces cerevisiae (Middlekauff et al. 1957) and it was on certain yeasts that actidione was first shown to have high toxicity (Whiffen, 1948).

\section{ME'THODS}

Throughout the experiments, media containing actidione (Upjohn) were sterilized by autoclaving for $10 \mathrm{~min}$. at $121^{\circ}$. Conidiating colonial strains were selected for use as the starting strains. They were either double mutants or triple mutants, all in the background of St Lawrence stocks $74 \mathrm{~A}$ and $73 \mathrm{a}$. The genotypes of these strains and the isolation numbers of the alleles involved are listed in Table 1 . The wildtype strains used in the present study were STA 4, a vegetative reisolate of $74 \mathrm{~A}$, and $\mathrm{Pa}$, derived from St Lawrence stocks by Perkins (1959).

For isolation of mutants, conidia from the sensitive strains were spread on the surface of medium N (Vogel, H. J., Microb. Genet. Bull. 13, 42) containing $10 \mu \mathrm{g}$. actidione/ml., which was supplemented with $1 \%$ sucrose and solidified by $1.5 \%$ Difco agar. The actidione concentration was the lowest at which no growth was observable when $10^{6}$ to $10^{7}$ conidia from the sensitive strains were spread on plates 
of graded concentrations of the antibiotic. The plated conidia were exposed to ultraviolet irradiation giving 50-75\% killing. Resistant colonies were selected after 5 or 6 days at $25^{\circ}$. Whenever more than one colony was found on the plates receiving conidia from the same strain, only one colony was selected to ensure that the mutants obtained had arisen from separate mutational events.

Each putative mutant was progeny tested by crossing with a standard wild-type strain. Ascospores were collected as unordered tetrads (Strickland, 1960) in order to detect whether the mutant strain was homokaryotic for the mutant allele.

The techniques used for crossing, for isolating random spores, and for linkage detection were similar to those used by Perkins (1959). Dry-weight assays (Ryan, 1950) were employed with modifications to measure quantitatively the sensitivity of different homokaryotic and heterokaryotic strains to this antibiotic. Conidial suspensions were inoculated into $125 \mathrm{ml}$. Erlenmeyer flasks containing $20 \mathrm{ml}$. of medium $\mathbf{N}$ with or without actidione. Dry weights were measured after four days at $25^{\circ}$.

\section{RESULTS}

Position of loci. Seven actidione-resistant strains of independent origin were isolated and subjected to transmission tests. In each case, a 2:2 segregation for resistance and sensitivity was demonstrated in individual unordered tetrads obtained from a mutant $\times$ wild-type cross, where two or three known, visible markers were also segregating. It appeared in each case that resistance had arisen through the mutation of a single Mendelian factor. Subsequent tests assigned the seven mutants to two independent loci: act-1 and act-2. The assignment was based on the localization of the allele $\mathrm{KH} 52$ in linkage group I and KH 53 in group V, and by subsequent tests of the remaining mutants with these two for allelism. Two mutants were tentatively considered to be allelic, if no wild type was observed within a small population taken from the progeny of a mutant $\times$ mutant cross. (The population sizes were $37,62,40,46$ and 29 of the crosses $\mathrm{KH} 51 \times \mathrm{KH} \mathrm{52}$, $\mathrm{KH} 54 \times \mathrm{KH} \mathrm{52}$, KH $56 \times \mathrm{KH} \mathrm{53,} \mathrm{KH} 57 \times \mathrm{KH} 52$, and $\mathrm{KH} 58 \times \mathrm{KH} 52$, respectively.) Table 1 gives the locus to which each mutant was assigned, and the original strain from which each mutant was isolated.

Table 1. Loci and strains of origin of actidione-resistant mutants

\begin{tabular}{|c|c|c|}
\hline Isolation no. & Locus & Strain of origin \\
\hline KH 51 & act -1 & $\operatorname{cr}(B 123): \operatorname{bal}(B 56) A$ \\
\hline КH 52 & act -1 & $\operatorname{cr}(B 123): \cot (C 102) A$ \\
\hline KH 53 & $a c t-2$ & $\operatorname{cr}^{L}: \cot (C 102): y \operatorname{lo}(Y 30539 y) A$ \\
\hline KH 54 & $a c t-1$ & $\operatorname{cr}(\boldsymbol{B} 123): \operatorname{bal}(\boldsymbol{B} 56) a$ \\
\hline KH 56 & $a c t-2$ & $\operatorname{cr}(\mathrm{B} 123): y \operatorname{lo}($ Y 30539y $) a$ \\
\hline KH 57 & $a c t-1$ & $c r^{L}, n i t-1(34547), \operatorname{aur}(34508) a$ \\
\hline KH 58 & act-1 & $\operatorname{cr}(B 123), \operatorname{rg}(B 53) a$ \\
\hline
\end{tabular}

Linkage data. Linkage data of act-1 and act-2 based on three-point crosses are given in Table 2 . The data indicated that the gene act-1 is located between nit-1 (nitrate-1) and aur (aurescent) in the right arm of linkage group I, and that act-2 is close to $s p$ (spray) in the right arm of linkage group $\mathrm{V}$.

The double mutant. The double mutant was synthesized by crossing act-1 ( $\mathrm{KH} \mathrm{52}$ ) $\times$ act-2 (KH 53). A 3:1 ratio for the resistant and sensitive phenotypes was 
observed in the progeny of such a cross, as expected on the basis of independent assortment of genes at these two loci. Among the resistant segregants, one-third were apparently slower in growth in the minimal slants as compared with the

Table 2. Three-point data on random segregants from crosses involving act-1 and act-2

\begin{tabular}{|c|c|c|c|c|c|c|}
\hline \multirow[b]{2}{*}{$\begin{array}{l}\text { Zygote genotype and } \\
\text { recombination percentage }\end{array}$} & \multirow[b]{2}{*}{$\begin{array}{c}\text { Parental } \\
\text { combina- } \\
\text { tions }\end{array}$} & \multicolumn{3}{|c|}{ Recombinations } & \multirow[b]{2}{*}{$\begin{array}{l}\text { Total and } \\
\text { percentage } \\
\text { germina- } \\
\text { tion }\end{array}$} & \multirow[b]{2}{*}{$\begin{array}{c}\text { Marker } \\
\text { isolation } \\
\text { number }\end{array}$} \\
\hline & & $\begin{array}{c}\text { Singles, } \\
\text { region } \\
1\end{array}$ & $\begin{array}{c}\text { Singles, } \\
\text { region } \\
2\end{array}$ & $\begin{array}{c}\text { Doubles, } \\
\text { regions } \\
1 \text { and } 2\end{array}$ & & \\
\hline$a c t-1$ & 24 & 3 & 5 & 3 & 63 & В 123 \\
\hline cr $17.5+17.5$ & 21 & 4 & 2 & 1 & $63 \%$ & $\begin{array}{l}\text { KH 52 } \\
34508\end{array}$ \\
\hline$a c t-1$ & 33 & 2 & 1 & 0 & 64 & 34547 \\
\hline${ }_{6 \cdot 3}^{n i t-1_{4.7}}+{ }^{a u r}$ & 24 & 2 & 2 & 0 & $64 \%$ & $\begin{array}{l}\text { KH 52 } \\
34508\end{array}$ \\
\hline$a c t-2$ & 39 & 15 & 9 & 1 & 140 & 33933 \\
\hline${ }_{25 \cdot 7}^{l y s-1}+\underset{14 \cdot 3}{\text { inos }}$ & 47 & 19 & 9 & 1 & $72 \%$ & $\begin{array}{l}\text { KH 53 } \\
37401\end{array}$ \\
\hline inos & 42 & 1 & 3 & 1 & 97 & KH 53 \\
\hline${ }_{\mathbf{a c t}-2}{ }^{+}{ }_{6 \cdot \mathbf{2}^{+}}^{+}$ & 47 & 1 & 2 & $\mathbf{0}$ & $32 \%$ & $\begin{array}{l}\text { B } 132 \\
37401\end{array}$ \\
\hline
\end{tabular}

Numbers of progeny are given in the body of the table. The numbers in the top row of each cross represent the genotypes which contain the plus allele of the left-most marker. Regions are numbered from left to right, and isolation numbers in the last column are listed in the same order. In the last cross the order of $a c t-2$ and $s p$ is arbitrary. For descriptions of markers, see Perkins (1959) and Barratt, Newmeyer, Perkins \& Garnjobst (1954).

Table 3. Test crosses identifying double mutants from the cross act-1 (KH 52) $\times$ act-2 (KH 53)

\begin{tabular}{|c|c|c|c|c|}
\hline \multirow[b]{2}{*}{ Cross } & \multirow[b]{2}{*}{ Type of eross } & \multicolumn{3}{|c|}{ Progeny class* } \\
\hline & & A & $\mathbf{B}$ & $\mathrm{C}$ \\
\hline 1$)$ & & 28 & 0 & 22 \\
\hline 2 & & 27 & 0 & 28 \\
\hline 3 & & 25 & 0 & 37 \\
\hline 4 & Normal-growing, resistant $\times$ sensitive & 34 & 0 & 30 \\
\hline 5 & & 26 & 0 & 32 \\
\hline 6 & & 23 & 0 & 25 \\
\hline 7 & & (38 & 0 & 32 \\
\hline 8 & & (35 & 17 & 14 \\
\hline 9 & Slow-growing, resistant $\times$ sensitive & 33 & 24 & 11 \\
\hline 10$)$ & & 126 & 16 & 10 \\
\hline
\end{tabular}

* $\mathrm{A}=$ Resistant to actidione $(\mathbf{1 0} \mu \mathrm{g} . / \mathrm{ml}$.$) , normal growth in the minimal slants.$

$\mathrm{B}=$ Resistant to actidione $(10 \mu \mathrm{g} . / \mathrm{ml}$.), slow growth in the minimal slants.

$\mathrm{C}=$ Sensitive to actidione $(10 \mu \mathrm{g} . / \mathrm{ml}$.), normal growth in the minimal slants.

remaining two-thirds, and with the sensitive segregants. In order to separate the double mutant from the single mutants, seven normal-growing, resistant types and three slow-growing, resistant types were backcrossed to the wild types (Table 3). While the former type of crosses gave $1: 1$ segregation for resistance and sensitivity and no slow-growing segregants, the latter type gave 3:1 segregation for resistance 
and sensitivity, with a recurrence of the slow-growers constituting one-third of the resistant types, indicating that the slow-growing, resistant types are double mutants. The slow-growing segregants were also observed among the progeny of crosses involving other combinations of alleles at act-1 and act- 2 (KH $52 \times \mathrm{KH} \mathrm{56}$, KH $54 \times \mathrm{KH} \mathrm{53,} \mathrm{KH} 57 \times \mathrm{KH} \mathrm{53,} \mathrm{KH} 58 \times \mathrm{KH} \mathrm{53).} \mathrm{All} \mathrm{the} \mathrm{slow} \mathrm{growers} \mathrm{were}$ resistant, and, in all the cases, they represented about one-fourth of the progeny, as expected if slow growth is characteristic of the double mutant.

Table 4. Mycelium dry reights $(\mathrm{mg})$ of four actidione genotypes in medium $N$ with different concentrations of actidione*

\begin{tabular}{|c|c|c|c|c|c|c|c|c|c|c|c|c|c|c|c|c|c|}
\hline \multirow[b]{2}{*}{ Genotype } & \multicolumn{17}{|c|}{ Actidione concentration $(\mu \mathrm{g} . / \mathrm{ml})}$. \\
\hline & 0 & $0 \cdot 1$ & $0 \cdot 2$ & $0 \cdot 3$ & 0.4 & 0.5 & 1 & 2 & 4 & 10 & 25 & 50 & 100 & 200 & 300 & 400 & 500 \\
\hline Wild-type & 90 & 64 & 43 & 28 & 22 & 18 & 9 & $\mathbf{3}$ & 0 & 0 & - & - & - & - & 一 & - & - \\
\hline$a c t-1$ & 93 & - & - & - & - & - & - & - & - & 56 & 34 & 22 & 12 & 10 & 3 & 2 & 1 \\
\hline act -2 & 88 & - & - & - & - & - & - & - & 一 & 71 & 38 & 24 & 14 & 10 & 3 & 2 & 2 \\
\hline$a c t-1 ; a c t-2$ & 16 & 一 & - & - & - & - & - & - & - & 20 & 17 & 18 & 21 & 16 & 15 & 14 & 13 \\
\hline
\end{tabular}

Sensitivity of homokaryons. The scoring for resistance and sensitivity was carried out on minimal slants into which actidione had been added at the concentration of $10 \mu \mathrm{g} . / \mathrm{ml}$. A clear-cut qualitative difference could be detected this way without paying special attention to the size of inoculum or time of scoring, since the sensitive strains did not adapt appreciably. This was true when either act-1 or act-2 strains were compared with the wild-type strains. Between act-1 and act-2, however, there appeared to be little difference in sensitivity to the antibiotic. Quantitative measurement was accomplished by dry-weight assays in a series of actidione concentrations. In addition to wild type $(\mathrm{Pa})$ and the single mutants $(\mathrm{KH} 52$ and KH 53), the double mutant ( $\mathrm{KH} \mathrm{52;} \mathrm{KH} \mathrm{53)} \mathrm{was} \mathrm{also} \mathrm{tested} \mathrm{(Table} \mathrm{4).} \mathrm{The} \mathrm{results}$ showed that while the concentrations the single mutants can withstand are about the same, they are roughly a hundred times higher than those allowing detectable growth of wild type. The double mutant produces approximately as much mycelium in the presence of actidione as in the absence within the concentration ranges tested. The low mycelium production in liquid minimal medium by the double mutant corresponds to its slow growth on minimal agar.

Sensitivity of heterokaryons. Three types of heterokaryons were made: (1) act-1 with,$+(2)$ act- 2 with + , and (3) act-1 with act-2. The alleles KH 52 and KH 53 were used. The auxotrophic alleles used in establishing all three types of heterokaryons were pan-1 (pantothenic-1, 5531), inos (inositol, 37401), and $n t$ (nicotinictryptophan, C 86). The component nuclei of some heterokaryons were also marked with either $a l-2$ (albino-2, 15300) or ylo (yellow, Y 30539y).

The sensitivity of any particular heterokaryon was tested on minimal slants containing actidione. It was found that both act- 1 with + and act- 2 with + heterokaryons consistently expressed the resistant phenotype when they were tested on actidione. This suggested that both act-1 and act-2 are dominant over their corresponding wild-type alleles. The dominance was further supported by the quantitative data obtained from dry-weight assays. As shown in Table 5, the heterokaryons 
of act- 1 with + and of $a c t-2$ with + produced almost as much mycelium in actidione as did the act-1 and act-2 homokaryons.

The act-1 with act-2 heterokaryons were resistant in phenotype, as would be expected if the mutant genes constituting these heterokaryons are dominant. This demonstrates that at least one of the two mutant genes shows a high degree of dominance, i.e. that it is not just partially dominant over its + allele.

Table 5. Production of mycelium by various actidione genotypes in medium $N$ with and without actidione

\begin{tabular}{|c|c|c|}
\hline & \multicolumn{2}{|c|}{$\begin{array}{l}\text { Dry wt. of mycelium (mg.) } \\
\text { in minimal medium* }\end{array}$} \\
\hline Genotype & $\begin{array}{r}\text { Without } \\
\text { Phenotypet actidione }\end{array}$ & $\begin{array}{l}\text { With } \\
10 \mu \mathrm{g} . / \mathrm{ml} \text {. } \\
\text { actidione }\end{array}$ \\
\hline
\end{tabular}

Homokaryons

\begin{tabular}{|c|c|c|c|}
\hline Wild-type & $\mathbf{S}$ & 113 & 0 \\
\hline act-1 & $\mathbf{R}$ & 108 & 85 \\
\hline act-2 & $\mathbf{R}$ & 110 & 86 \\
\hline$a c t-1 ; a c t-2$ & $\mathbf{R}$ & 18 & 18 \\
\hline \multicolumn{4}{|l|}{ Heterokaryons } \\
\hline act-1;pan-1(a)+al-2; $\operatorname{inos}(a)$ & $\mathbf{R}$ & 103 & 73 \\
\hline act- $1 ; n t(A)+a l-2 ; p a n-1(A)$ & $\mathbf{R}$ & 106 & 80 \\
\hline act-2; pan-1 $(a)+y l o ; \operatorname{inos}(a)$ & $\mathbf{R}$ & 101 & 7 \\
\hline$a c t-2 ; \operatorname{pan}-1(a)+a l-2 ; \operatorname{inos}(a)$ & $\mathbf{R}$ & 107 & 7 \\
\hline$a c t-1 ; n t(A)+a c t-2 ; y l o ; i n o s(A)$ & $\mathbf{R}$ & 95 & 7 \\
\hline$a c t-1 ; n t(a)+a c t-2 ; p a n-1(a)$ & $\mathbf{R}$ & 95 & $7:$ \\
\hline
\end{tabular}

* Values are averages for two replicate flasks.

$\dagger$ As scored in 3 inch minimal slants containing $10 \mu \mathrm{g} . / \mathrm{ml}$. actidione. $\mathrm{S}=$ Sensitive, $\mathbf{R}=$ resistant.

\section{DISCUSSION}

The occurrence of a dominant mutation within a single nucleus in a multinucleate conidium produces a heterokaryotic conidium capable of giving rise to a culture with the dominant phenotype. In the present study, heterokaryotic conidia containing both resistant and sensitive nuclei can be picked up from the actidione plates because the alleles for resistance are dominant. On the other hand, if the mutant allele for resistance were recessive, the presence of such an allele in a multinucleate conidium would be phenotypically sensitive, and would, therefore, not be able to grow on the selective medium containing the antibiotic. The method used thus appears to favour the recovery of dominant, resistant mutations. The recovery of recessive mutant alleles for resistance on the selective medium would be possible under the condition that in a single conidium only the nucleus carrying the mutant allele survived u.v.-irradiation. The present result that resistant mutants are dominant does not, therefore, justify the conclusion that recessive mutants conferring resistance do not occur. In fact, recessive resistant mutants are not uncommon. For example, one of the three mutant alleles for acriflavine resistance reported in Aspergillus nidulans is a recessive allele (Roper \& Käfer, 1957), and, by use of heterogenotes, phage resistance (Lederberg, 1949) and streptomycin resistance (Lederberg, 1951) in Escherichia coli have been shown to be recessives. 
The mutant genes at both the act-1 and act-2 loci are phenotypically indistinguishable. The dominant nature of these mutants prevents testing for allelism in heterokaryons. The applicability of such dominant alleles for resistance to the automatic selection of mitotic segregants arising from diploid nuclei heterozygous for them, if a parasexual cycle does exist in Neurospora crassa, would depend upon whether the vegetative segregants can be distinguished from the diploid heterozygotes with respect to level of resistance. Such dominant mutant alleles would not give rise to the pseudo-wild types described by Mitchell, Pittenger \& Mitchell (1952) and by Pittenger (1954), since, if the presumed heterozygous disomic strains do arise from a cross, they would be mutant in phenotype.

The presence of at least one wild-type allele at either one of the two actidione loci in a single nucleus appears to be essential for normal growth in the absence of actidione, although when both wild-type alleles are substituted by the mutant alleles, a higher degree of resistance results. This is inferred from the observation that the double mutant is slow-growing while the heterokaryon act-1+act- 2 is not.

The actidione-resistant mutants should prove to be useful markers in recombination studies, for they are located in well-marked chromosome arms (Perkins, 1959; Strickland, Perkins \& Veatch, 1959), and the scoring for the difference in resistance and sensitivity is clear-cut. Their biochemical and physiological actions, and usefulness in other respects, largely remain to be explored.

The author is indebted to Drs David D. Perkins, Dorothy Newmeyer, and Noreen E. Murray for their interest and criticism during this study and in the preparation of the manuscript. This work was supported by U.S. Public Health Service Training Grant 2G-158 and Research Grant AI-01462.

\section{REFERENCES}

Barratt, R. W., Newmeyer, D., Perkins, D. D. \& Garnjobst, L. (1954). Map construction in Neurospora crassa. Advanc. Genet. 6, 1.

Demerec, M. (1945). Production of Staphylococcus strains resistant to various concentrations of penicillin. Proc. nat. Acad. Sci., Wash. 31, 16.

Hsu, K. S. (1962). Genetic basis of drug-resistant mutants in Neurospora. Genetics, 47, 961.

Lederberg, J. (1949). Aberrant heterozygotes in Escherichia coli. Proc. nat. Acad. Sci., Wash. 35, 178.

Lederberg, J. (1951). Streptomycin resistance: a genetically recessive mutation. J. Bact. $61,549$.

Midolekauff, J. E., Hino, S., Yang, S. P., Lindegren, G. \& Lindegren, C. C. (1957). Gene control of resistance vs. sensitivity to actidione in Saccharomyces. Genetics, 42, 66.

Mitchell, M. B., Pittenger, T. H. \& Mitchell, H. K. (1952). Pseudo-wild types in Neurospora crassa. Proc. nat. Acad. Sci., Wash. 38, 569.

Perkins, D. D. (1959). New markers and multiple point linkage data in Neurospora. Genetics, 44, 1185.

Pittenger, T. H. (1954). The general incidence of pseudo-wild types in Neurospora crassa. Genetics, 39, 326.

Roper, J. A. \& KÄFER, E. (1957). Acriflavine-resistant mutants of Aspergillus nidulans. J. gen. Microbiol. 16, 660.

Ryan, F. J. (1950). Selected methods of Neurospora genetics. Meth. med. Res. $3,51$.

Strickland, W. N. (1960). A rapid method for obtaining unordered Neurospora tetrads. J. gen. Microbiol. 22, 583. 
Strickland, W. N., Perkins, D. D. \& Veatch, C. C. (1959). Linkage data for group V markers in Neurospora. Genetics, 44, 1221.

Whiffen, A. J. (1948). The production, assay, and antibiotic activity of actidione, an antibiotic from Streptomyces griseus. J. Bact. 56, 283.

Since this paper was submitted, the isolation of similar mutants has been reported by Howe \& Terry (1962).

Howe, H. B., Jr. \& Terry, C. E., Jr. (1962). Genetic studies of resistance to chemical agents in Neurospora crassa. Canad. J. Genet. Cytol. 4, 447. 